RESEARCH PAPER

\title{
Which smokers use the smoking cessation Quitline in Hong Kong, and how effective is the Quitline?
}

\author{
A S M Abdullah, T-H Lam, S S C Chan, A J Hedley
}

Tobacco Control 2004;13:415-421. doi: 10.1136/tc.2003.006460

See end of article for authors' affiliations .....................

Correspondence to: Professor Tai-Hing Lam, Department of Community Medicine, The University of Hong Kong, 5/F Academic Block, New Medical Complex, 21

Sassoon Road, Hong Kong SAR; commed@hkucc.hku. hk

Received 20 October 2003 Accepted 14 July 2004
Objective: To describe the characteristics of the Chinese subjects who utilised the first telephone smoking cessation service in Hong Kong, and to evaluate its effectiveness.

Methods: The Quitline provided Hong Kong residents with free telephone smoking cessation services which was publicised through a press conference, media reports, pamphlets, and posters at public and private hospitals and clinics. Callers who completed an initial interview from 13 December 2000 to 31 May 2002 were included. Smokers were interviewed using a structured record sheet and provided with stage matched counselling. A follow up interview was carried out after six months. Analysis was conducted by intention-to-treat.

Results: Of the 1120 callers who completed initial assessments, 1047 were current smokers and 872 consented to follow ups. Compared to the general smoking population, the Quitline attracted more of those who were female, younger, single, unemployed, higher educated, smoking more than 20 cigarettes per day, and those with quitting experience. At six months, 12\% (95\% confidence interval 10\% to 15\%) of the participants reported that they had not smoked a cigarette for the past seven days. A stepwise logistic regression model showed that the use of nicotine replacement therapy at the present attempt to quit, having made one or more serious attempts to quit in the past, perceiving less difficulties in quitting, and smoking the first cigarette at age 15 years or above were significant predictors of quitting.

Conclusion: This first Quitline in Asia appears to be acceptable to Chinese smokers, with quit rate comparable to those of better funded Quitlines in the West. A low cost Quitline is a promising model for smoking cessation services in the East.
S moking is the major preventable cause of death in Hong Kong, leading to about 6000 deaths annually and accounting for about one fifth of all deaths. ${ }^{1}$ Quitting smoking has significant health benefits, ${ }^{2}$ and effective strategies are available to support quitting. ${ }^{3}$ Among the many services that are available to support smoking cessation, Quitline services (telephone based services with smokers' direct access to smoking cessation counsellors) were reported to be effective in the USA, ${ }^{5-7}$ the $\mathrm{UK}^{8}{ }^{8}$ and Australia. ${ }^{10}{ }^{11}$ Quitlines can deliver cessation services to those who need help at convenient times and with less resources than other methods. The telephone format encourages people who are reluctant to obtain help from usual services to seek service, ${ }^{12}{ }^{13}$ as soon as they make decision to seek help. There is evidence that telephone based counselling is helpful to the general smoking population who want to receive direct advice or counselling but try to avoid face-to-face contact. ${ }^{3}{ }^{14}$ However, a major criticism is that Quitline services rely on callers to be proactive.

The Hong Kong Special Administrative Region (HKSAR), the most westernised and economically advanced city in China, has a population of 6.5 million, $95 \%$ of whom are ethnic Chinese. In 1998, there were 0.8 million daily smokers-about $15 \%$ of the population aged 15 years or above. ${ }^{15}$ Before the Quitline was established in December 2000, no telephone based smoking cessation service was available in Hong Kong or in mainland China.

There is a lack of smoking cessation services in the AsiaPacific region, particularly in China with more than 300 million smokers. Moreover, information on the predictors of quitting among Quitline callers is lacking around the world. This paper describes the characteristics of the smokers who used the Hong Kong Quitline. We also examined predictors of smoking cessation among Quitline callers, and compared the service's quit rate with Quitlines in the West.

\section{METHODS \\ Quitline programme}

The Quitline was operated as a pilot programme by the Department of Community Medicine and Nursing Studies of the University of Hong Kong in collaboration with Hong Kong Council on Smoking and Health. The Quitline was publicised, with a small budget, through press conference, media reports, pamphlets, posters at public and private hospitals and clinics, and through the website of the Hong Kong Council on Smoking and Health. Free services were available for 38 hours per week (Monday to Friday from 2 pm to $8 \mathrm{pm}$ and Saturdays from 10 am to $6 \mathrm{pm}$ ) by trained bilingual (English and Chinese) counsellors. Smokers were interviewed using a structured record sheet, and were provided with stage matched counselling ${ }^{16}$ using a structured protocol with each session lasting for about 20 minutes. Callers who provided mailing addresses also received cessation related materials by post.

\section{Subjects}

The potential subjects were current smokers who called the Quitline from 13 December 2000 to 31 May 2002 and completed an initial assessment about their smoking status and intention to quit. In this report we included those smokers who wanted to receive counselling regardless of their intention to quit, and who gave verbal consent and provided a contact telephone number for a follow up (fig 1). Ethical approval for this study was obtained from the ethics committee of the Faculty of Medicine, the University of Hong Kong. 


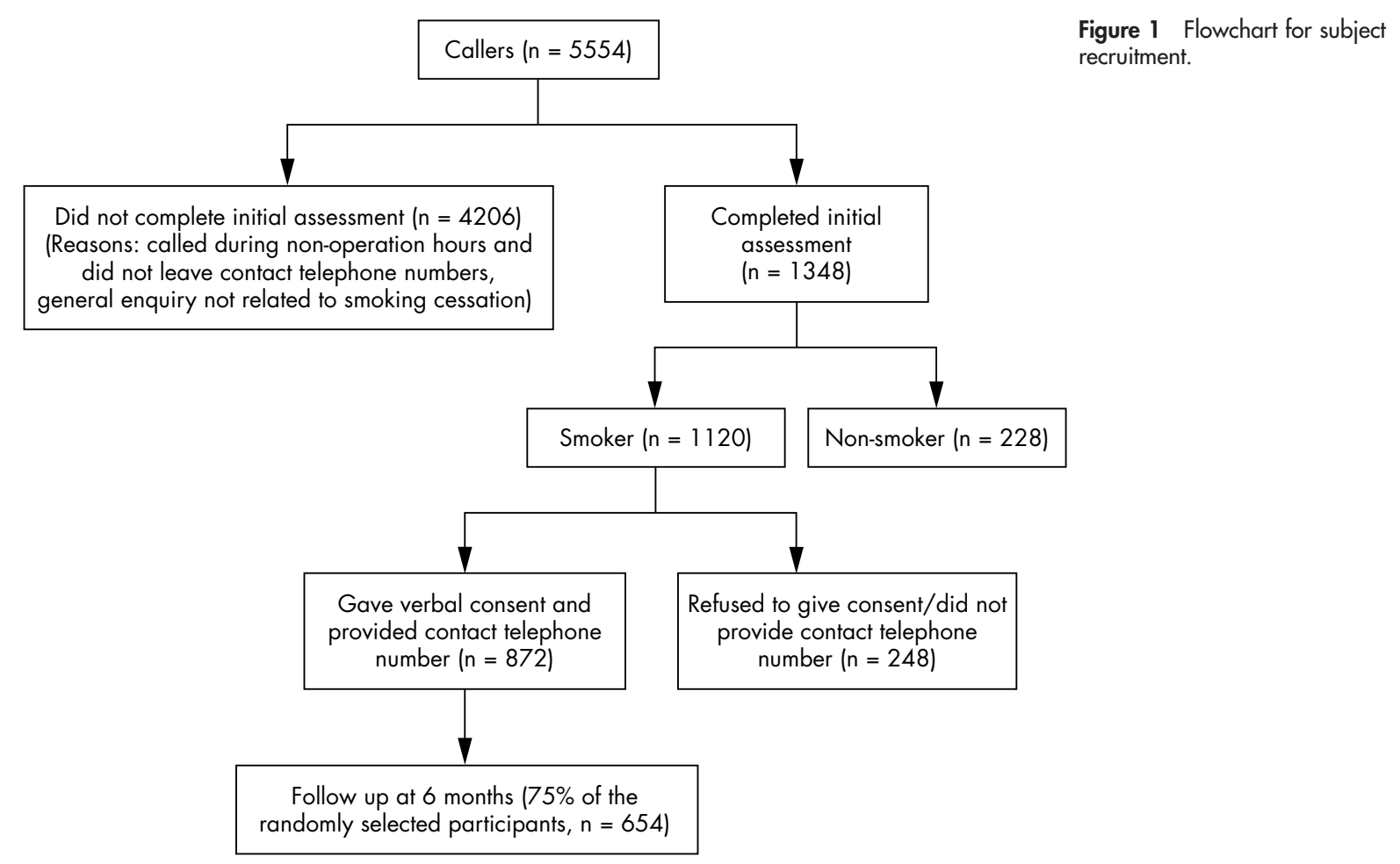

\section{Data collection}

The record sheet gathered participants' demographic information (sex, age, marital status, educational attainment, occupation, and personal and household monthly income), smoking history (smoking status, other household members' smoking status, the age that the participant started smoking regularly, and the average number of cigarettes smoked per day), nicotine dependence level (using the six question Fagerstrom tolerance questionnaire ${ }^{17}$ ), quitting history (whether the participant had ever seriously tried to stop smoking, the number of serious attempts, and the longest duration of not smoking during the latest attempt), and intention to quit based on the Prochaska's model. ${ }^{16}$

To assess respondent's perceived risk of tobacco use, we asked two questions: "Do you think smoking is harmful to health?" and "Do you think second hand smoking is harmful to health?" We also asked whether subjects used any form of nicotine replacement therapy (NRT) in the current quitting attempt. Adherence to stage matched counselling recommendations was assessed by asking: "Did you completely follow the counselling advice as recommended by counsellors?" All the response categories above were yes or no.

To compare the characteristics of the Quitline callers with those of the general population, we used data from the 2000 Thematic Household Survey (THS) ${ }^{18}$ of the Government Census and Statistics Department, which collected information on cigarette smoking patterns and other social information on the general population aged 15 or above from October to November 2000. Systematic random sampling was used and 11779 persons were interviewed; of these, $14.4 \%$ (1692) were current smokers (daily and occasional smokers). We compared our sample with these current smokers, who should be representative of those in the general population.

\section{Follow up assessment}

A follow up interview was carried out at six months for a $75 \%$ (654/872) random sample. We could not follow up all participants because of resource limitations. We did not invite those smokers who reported cessation for biochemical validation, because biochemical tests are considered uninformative in low intensity interventions ${ }^{5}$ such as this Quitline and we expected very few would turn up for validation.

\section{Analysis}

The data were analysed using SPSS for Windows version 11.0. The difference between smokers who called the Quitline and the general smoking population in Hong Kong and the characteristics of quitters and non-quitters were compared by $\chi^{2}$ tests. The variables that were significant in the univariate analysis were tested by forward stepwise logistic regression to identify predictors for quitting and to estimate adjusted odds ratios and $95 \%$ confidence intervals (CI). We used an intention-to-treat analysis (that is, all cases analysis) to assess the quit rate. Follow up variables with missing data were set to their baseline values. We also repeated the analysis on predictors for quitting by including only those whose outcome data were available at follow up. A probability value of $\mathrm{p}<0.05$ (two tailed) was considered significant. Since the results were similar in the two analyses (that is, by intention-to-treat and by including only those with outcome data), we only reported results based on the intention-to-treat analysis.

Smoking cessation was measured by asking subjects whether they had smoked any cigarette during the past seven days at the six month follow up interview (point prevalence quit rate). ${ }^{2}$ Those who answered "no" were defined as quitters without any biochemical validation. All subjects who could not be contacted at follow up were considered to have continued smoking. For comparison with other studies, we reported a number of outcomes (analysed both by intention-to-treat and otherwise), ranging from a 24 hour quit rate to six months continuous quit rate.

\section{RESULTS}

\section{Users of Quitline}

Of the 5554 calls received by the Quitline over the study period, $3 \%$ were repeat calls, $5 \%$ were calls enquiring about the nature of the Quitline service, 68\% were calls received 
Table 2 Smoking status using different outcome indicators among participants at the six month follow up interview

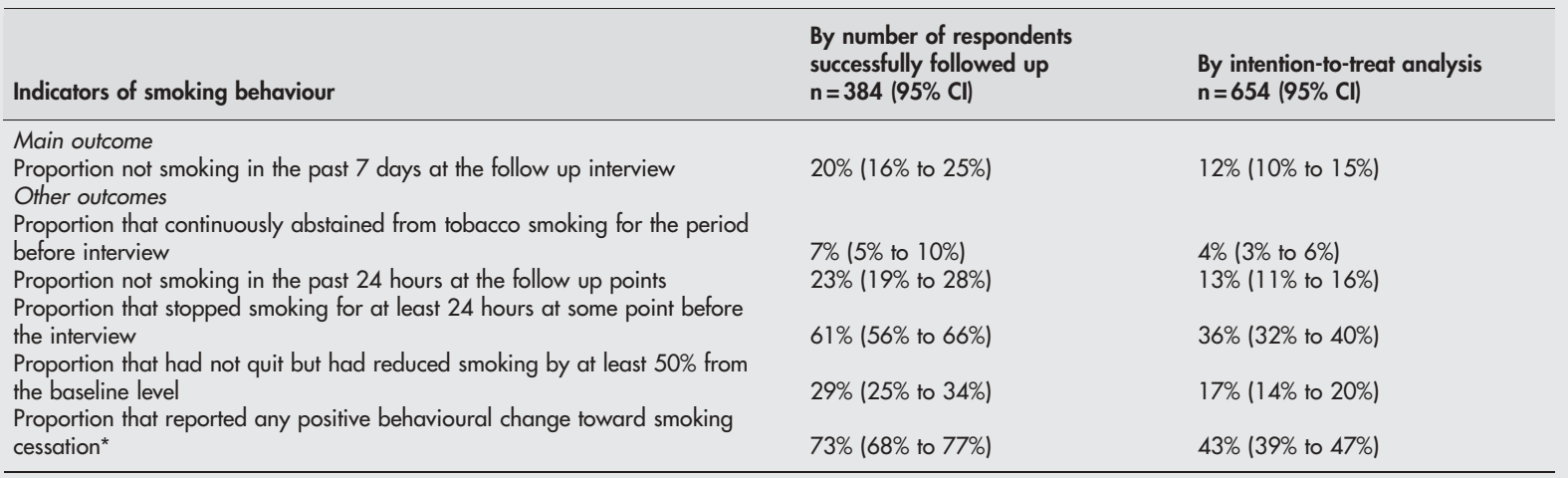

*Positive behavioural change refers to not smoking at follow up or having quit for at least a day or reduced cigarette consumption by at least $50 \%$.

$\mathrm{Cl}$, confidence interval.

less educated could be due to their lack of interest in quitting, or because the Quitline information failed to reach them. A lower education level was also associated with not calling in California. ${ }^{13}$ Because we promoted our Quitline with low cost and opportunistic marketing strategies such as media interviews, feature articles, and posters distributed to hospitals or clinics rather than paid television advertisements or other targeted promotional campaigns which are expensive, the lack of awareness among those who had less access to written media materials was expected. Specific promotional campaigns should be designed to promote Quitline's existence and should target the vulnerable groups such as the less educated and elderly smokers. Any new programmes should be systematically evaluated.

We also found that the Quitline smokers were more addicted than smokers in the general population, as indicated by their higher daily cigarette consumption..$^{20}$ Furthermore, more than three quarters of the Quitline smokers had seriously tried to stop smoking at least once in the past as compared to only about half in the general population. These findings are in line with those of the California Smokers' Helpline. ${ }^{13}$ This suggests that addicted smokers who have unsuccessfully tried to quit in the past understand the difficulties of quitting without any professional help and are more eager to receive support when available. As heavy smokers are less likely to be successful in quitting without pharmacological help, provision for pharmacological support should be considered in future Quitline programmes to enhance counselling. ${ }^{21}$ Special efforts are also needed to encourage more of the light and less addicted smokers to utilise the Quitline.

We were not able to reach about $68 \%$ of the callers to the Quitline, because they called during non-operation hours and did not leave a message with contact information. A small proportion of them might have called back again during operation hours. This probably indicates that a substantial proportion of the public was seeking smoking cessation services during both morning and late hours and on Sundays. The future operation of the Quitline should revise hours of operation to better suit the needs of the callers. Furthermore, only $24 \%$ of the callers in our Quitline completed the initial assessment, which is lower than that reported in the Massachusetts Quitline (40\%). ${ }^{19}$ This might be due to the larger volume of calls that we received during non-operation hours.

Our findings indicate that the Quitline concept, which had been effective for US, ${ }^{5-7}$ British, $^{89}$ and Australian ${ }^{10}{ }^{11}$ smokers, is also effective for Chinese smokers. However, there are difficulties in comparing the quit rates among studies due to the differences in the definitions of quit rate, the target populations, and follow up periods (see appendix, table Al (to view the appendix please visit the Tobacco Control website-http://www.tobaccocontrol.com/supplemental)).

Although the US Clinical Practice Guidelines use the seven day point prevalence abstinence rate or continuous abstinence rate, calculated by intention-to-treat analysis with or without validation at five or more months follow up, as the main outcome measure in smoking cessation, ${ }^{12}$ only the Quitlines of Western NewYork State ${ }^{6}$ and California ${ }^{5}$ and two other targeted Hotlines for young mothers ${ }^{22}$ and African Americans $^{23}$ used such a definition. Moreover, the Western New York State and the California Quitlines included only motivated callers in the study and the targeted Hotlines recruited smokers through extensive media campaigns, thus limiting their comparability to other Quitlines. The Australian Quitline $^{11}$ reported the continuous abstinence rate at six months $(7.8 \%)$ without using intention-to-treat analysis. All other Quitlines targeted at the general smoking population ${ }^{5-11}$ or specific population groups ${ }^{22-24}$ reported 24 hour point prevalence quit rates or other quit rates (for example, one month or three month point prevalence quit rates). Only the Western New York State Quitline ${ }^{6}$ reported biochemically validated quit rates. Therefore, our Quitline is the first to report a quit rate $(12 \%)$ for all callers (regardless of their readiness to quit) based on intention-to-treat. While different measures could be used to meet local needs and targets, the main outcome should be reported following a standard definition for international comparison.

Although the Western New York State Quitline ${ }^{6}$ included motivated smokers, its seven day point prevalence quit rate $(12 \%)$ at six month follow up is identical to ours. The continuous abstinence rate at six months (12.8\%) in California $^{5}$ was higher than the continuous abstinence rate (4\% by intention-to-treat) in our Quitline. This is probably due to the differences in the intensity of the counselling session provided in California (seven sessions versus one session in our Quitline) and the inclusion of motivated callers only. Note that California is also the state with the most successful and best funded tobacco control measures in the USA. In Australia, the continuous abstinence rate $(8 \%$ without intention-to-treat) at a six month follow up was also comparable to our six month continuous abstinence rate (7\% without intention-to-treat). Therefore, our result is comparable to or even better than some similar programmes abroad.

We found only six independent predictors of quitting by including all cases in the analysis, which were adhering to counselling recommendations, using NRT at the present attempt to quit, having one or more serious attempts to quit in the past, smoking 10 or less cigarettes daily, smoking the 
Table 3 Demographics, lifestyle, and quitting related factors among quitters and nonquitters $(n=654)$

\begin{tabular}{|c|c|c|c|}
\hline \multirow[b]{2}{*}{ Characteristics } & \multirow{2}{*}{$\begin{array}{l}\text { Non-quitter } \\
\text { ( } n=576 \text { ) } \\
n \text { (Row \%) }\end{array}$} & \multirow{2}{*}{$\begin{array}{l}\text { Quitter } \\
\text { (n=78) } \\
\text { n (Row \%) }\end{array}$} & \multirow{2}{*}{$\begin{array}{l}\text { p Value for } \\
\chi^{2} \text { tests }\end{array}$} \\
\hline & & & \\
\hline \multicolumn{4}{|l|}{ Demographics } \\
\hline \\
\hline Male & $432(87)$ & $65(13)$ & \\
\hline Female & $142(92)$ & $13(8)$ & 0.12 \\
\hline \multicolumn{4}{|l|}{ Marital status } \\
\hline Single & $233(91)$ & $24(9)$ & \\
\hline Married/cohabiting & $308(86)$ & $51(14)$ & \\
\hline Widowed/separated/divorced & $26(90)$ & $3(10)$ & 0.18 \\
\hline \multicolumn{4}{|l|}{ Occupational status } \\
\hline Housewife & $31(89)$ & $4(11)$ & \\
\hline Full time student/retired/unemployed & $130(83)$ & $26(17)$ & \\
\hline Currently employed & 400 (89) & $48(11)$ & 0.15 \\
\hline \multicolumn{4}{|l|}{ Age (years) } \\
\hline 30 or below & $215(90)$ & $25(10)$ & \\
\hline $31-40$ & $161(93)$ & $12(7)$ & \\
\hline $41-50$ & $115(86)$ & $19(14)$ & \\
\hline 51 or above & $71(77)$ & $21(23)$ & $<0.01$ \\
\hline \multicolumn{4}{|l|}{ Educational attainment } \\
\hline Primary school (grade 6) or below & $79(87)$ & $12(13)$ & \\
\hline Secondary school (grade 7-11) & $375(88)$ & 53 (12) & \\
\hline Matriculation (grade 12) or above & $109(89)$ & $13(11)$ & 0.83 \\
\hline \multicolumn{4}{|l|}{ Monthly personal income } \\
\hline HK\$0-9999 & $275(88)$ & $39(12)$ & \\
\hline HK\$10000 or more & $281(88)$ & 38 (12) & 0.85 \\
\hline \multicolumn{4}{|l|}{ Monthly household income } \\
\hline HK\$0-19999 & $351(88)$ & $47(12)$ & \\
\hline$H K \$ 20000$ or more & $193(87)$ & 28 (13) & 0.75 \\
\hline Tobacco use related & & & \\
\hline Daily cigarette consumption & & & \\
\hline$\leqslant 10$ & $137(82)$ & $31(18)$ & \\
\hline$\geqslant 11$ & $432(90)$ & $47(10)$ & $<0.01$ \\
\hline Nicotine dependency level $\dagger$ & & & \\
\hline Low & $169(86)$ & $27(14)$ & \\
\hline Moderate & $151(88)$ & $20(12)$ & \\
\hline Severe & $243(89)$ & $31(11)$ & 0.71 \\
\hline Number of smokers in the household & & & \\
\hline Nil & $369(89)$ & $47(11)$ & \\
\hline 1 or more & $203(87)$ & $31(13)$ & 0.46 \\
\hline Age started smoking the first cigarette & & & \\
\hline 14 or below & $159(94)$ & $10(6)$ & \\
\hline 15 or above & $411(86)$ & 68 (14) & $<0.01$ \\
\hline Age started smoking cigarette regularly & & & \\
\hline 14 or below & $122(94)$ & $8(6)$ & \\
\hline 15 or above & $448(87)$ & $70(13)$ & $<0.05$ \\
\hline Quitting history & & & \\
\hline Number of previous quitting attempt(s) & & & \\
\hline None & $130(96)$ & $5(4)$ & \\
\hline One or more & $440(86)$ & $73(14)$ & $<0.01$ \\
\hline Length of abstinence in the last attempt to & & & \\
\hline Less than a day or not at all & 49 (89) & $6(11)$ & \\
\hline$\geqslant 1$ day & $390(85)$ & $67(15)$ & 0.45 \\
\hline Perception of smoking & & & \\
\hline Perceive smoking as harmful to health & & & \\
\hline Yes & $560(88)$ & 75 (12) & \\
\hline No & $11(79)$ & $3(21)$ & 0.27 \\
\hline Perceive second hand smoking as harmfu & & & \\
\hline Yes & $530(89)$ & $68(11)$ & \\
\hline No & $41(80)$ & $10(20)$ & 0.08 \\
\hline Quitting smoking related† & & & \\
\hline Adherence to stage matched counselling & & & \\
\hline Yes & $171(77)$ & $52(23)$ & \\
\hline No & 405 (94) & $26(6)$ & $<0.001$ \\
\hline Joined other smoking cessation programn & & & \\
\hline Yes & $24(65)$ & $13(35)$ & \\
\hline No & $552(90)$ & $65(10)$ & $<0.001$ \\
\hline Used NRT at the present quitting attempt & & & \\
\hline Yes & $25(58)$ & $18(42)$ & \\
\hline No & $551(90)$ & $60(10)$ & $<0.001$ \\
\hline
\end{tabular}

A maximum of $5 \%$ data were missing for some items; US $\$ 1=H K \$ 7.8$.

†The nicotine dependence level was measured by the Fagerstrom scale, which is divided into 3 levels: low (score 0 $3)$, moderate (score 4-5), and severe (score $=6-10$ ).

$\ddagger$ This information was collected at the 6 month follow up interview.

NRT, nicotine replacement therapy. 
Table 4 Summary of logistic regression model (forward stepwise) to predict quitting at 6 month follow up

\begin{tabular}{|c|c|c|}
\hline \multirow[b]{2}{*}{ Independent variables } & \multicolumn{2}{|c|}{$\begin{array}{l}\text { Including all cases (by intention- } \\
\text { to-treat) }\end{array}$} \\
\hline & OR $(95 \% \mathrm{Cl})$ & p Value \\
\hline $\begin{array}{l}\text { Adherence to counselling } \\
\text { recommendations }\end{array}$ & 3.90 (2.28 to 6.69$)$ & $<0.001$ \\
\hline $\begin{array}{l}\text { Used NRT at the present quitting } \\
\text { attempt }\end{array}$ & 5.86 (2.75 to 12.48$)$ & $<0.001$ \\
\hline $\begin{array}{l}\text { Had one or more previous quitting } \\
\text { attempts }\end{array}$ & 3.44 (1.31 to 9.05$)$ & $<0.05$ \\
\hline Smoked 10 or less cigarettes per day & 2.50 (1.41 to 4.42$)$ & $<0.01$ \\
\hline $\begin{array}{l}\text { Started smoking the first cigarette at } \\
\text { age } 15 \text { or above }\end{array}$ & 2.33 (1.12 to 4.87$)$ & $<0.05$ \\
\hline Age (referent $=30$ years or under) & & $<0.01$ \\
\hline $31-40$ years & $0.54(0.25$ to 1.19$)$ & 0.11 \\
\hline $41-50$ years & 1.31 (0.63 to 2.72$)$ & 0.51 \\
\hline 51 years or over & 2.37 (1.15 to 4.89$)$ & $<0.05$ \\
\hline
\end{tabular}

first cigarette at age 15 or above, and being aged above 50 years. Other significant predictors in univariate analysis could have been excluded from the stepwise modelling because they were strongly associated with the predictors in the final model. Because different lists of predictors were examined in different studies, the significant predictors from stepwise modelling would not be identical. In addition to those that we identified, some studies ${ }^{725}$ reported other predictors of successful quitting, such as the age at which regular smoking began, joining other smoking cessation programmes, quitting for at least a day in the latest attempt to quit, nicotine dependency level, and educational attainment. We also found that the former two predictors were significant in univariate analysis. Although NRT was not given in this study, some of the smokers used NRT to support their attempt to quit. The higher success rate among those who used NRT supports the established effectiveness of NRT. ${ }^{26}$

Although interventions following Prochaska's stages of change model $^{16}$ have been reported to be effective in supporting quitting, a recent review reported ineffectiveness. ${ }^{27}$ However, we found no previous studies which examined or reported adherence to stage based interventions in relation to quitting outcome among Chinese smokers. We found that adherence to stage based smoking cessation intervention was a significant predictor of smoking cessation. This suggests that measures to improve adherence to counselling recommendations could improve quit rates. As most previous adherence studies in relation to smoking cessation intervention focused on adherence to pharmacological products with little emphasis on behavioural components, there is a need for randomised controlled trials to test what interventions would be effective in increasing adherence to behavioural interventions such as the "stage based intervention" used in the present study.

\section{Study limitations}

This study has several limitations. First, the data that we collected from the Quitline were based on the proactive calls of smokers who were less likely than the general populace to under-report their smoking related information. In contrast, the Thematic Household survey was based on household interviews, and smokers could have under-reported or misreported their smoking related information. Therefore, the comparison should be interpreted cautiously. Second, three trained nurse counsellors provided the stage based counselling which was manageable to ensure coherence in the coordination and the delivery of counselling. However,

\section{What this paper adds}

Prior research has reported the effectiveness of a smoking cessation Quitline among populations in the West. However very little information on this smoking cessation service was available in the literature from the East, especially from China with more than 300 million smokers. To the best of our knowledge, this is the first article that reports a smoking cessation Quitline from the East.

The findings of this study suggest that the smoking cessation Quitline is acceptable to Chinese smokers and the quit rate achieved by very low running and publicity costs is comparable to those of better funded Quitlines in the West. A low cost Quitline is a promising model for smoking cessation services in the East.

we are uncertain whether similar benefits could be achieved in a larger service with more counsellors and less opportunities for staff to compare and coordinate activity. Third, the reported quit rate was based on self reporting. However, the misreported rate for self reporting is relatively low $(<5 \%),{ }^{28}$ and self reporting has been used extensively as an outcome measure for studies on smoking cessation and exposure. ${ }^{28} 29$ Fourth, we conservatively used intention-to-treat analysis to determine the quit rate. It is possible that some smokers who were not available at follow up might have quit smoking and were unwilling to be followed up. Fifth, $41 \%$ of the subjects were lost to follow up. It was possible that those who continued with the follow up were different from those who were not. However, we have found no significant differences in the baseline demographic or smoking characteristics of the two groups.

In conclusion, the Quitline appears to be a useful and acceptable smoking cessation service for the Chinese in Hong Kong, which suggests the need for more Quitlines in other Chinese or Asian cities.

\section{ACKNOWLEDGEMENTS}

We received support from the Hong Kong Council on Smoking and Health for the promotion of the Quitline, and from the pharmaceutical companies Pharmacia \& Upjohn and Novartis in the production of publicity materials. The study was funded by the Health Care and Promotion Fund of the Government of the Hong Kong SAR.

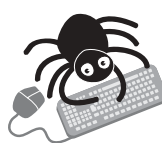

To view the appendix (table $A 1$ ) please visit the Tobacco Control website-http://www. tobaccocontrol.com/supplemental

\section{Authors' affiliations}

A S M Abdullah, T-H Lam, A J Hedley, Department of Community

Medicine, The University of Hong Kong, Hong Kong SAR

S S C Chan, Department of Nursing Studies, The University of Hong Kong

\section{REFERENCES}

1 Lam TH, Ho SY, Hedley AJ, et al. Mortality and smoking in Hong Kong: casecontrol study of all adult deaths in 1998. BMJ 2001;323:1-6.

2 Task Force on Community Preventive Services. Tobacco use prevention and control. Am J Prev Med 2001;20(suppl I): 1-88.

3 Lichtenstein E, Glasgow RE, Lando HA, et al. Telephone counselling for smoking cessation: rationales and meta-analytic review of evidence. Health Educ Res 1996;11:243-57.

4 Stead LF, Lancaster T. Telephone counselling for smoking cessation (Cochrane review). In:The Cochrane Library.Issue 4. Oxford: Update Software, 2002, http://www.cochranelibrary.com/cochrane/ [Accessed 1 June 2003].

5 Zhu SH, Christopher M, Anderson BA, et al. Evidence of real-world effectiveness of a telephone quitline for smokers. N Engl J Med 2002;347:1087-93 
6 Ossip-Klein DJ, Giovino GA, Megahed N, et al. Effects of a smokers' hotline: results of a 10-country self-help trial. J Consult Clin Psychol 1991;59:325-32.

7 Jaen CR, Cummings KM, Zielezny M, et al. Patterns and predictors of smoking cessation among users of a telephone hotline. Public Health Report 1993; 108:772-8

8 Platt S, Tannahill A, Watson J, et al. Effectiveness of antismoking telephone helpline: follow up survey. BMJ 1997;314:1371-5.

9 Owen L. Impact of telephone helpline for smokers who called during a mass media campagin. Tobacco Control 2000;9:148-54.

10 Borland R. Three-month follow up on callers to a telephone counselling service in 1987. In. Quit Evaluation Studies, 1989: Volume 3, Chapter 6, www.quit.org.au [Accessed 10 June 2003].

11 Wakefield M, Miler C. Evaluation of the national quitline service. In: Hassard K, eds. Australia's national tobacco campaign: evaluation report, Vol. 1. Canberra: Commonwealth Department of Health and Aged Care, 1999:83-106.

12 Public Health Service. Clinical practice guideline: Treating tobacco use and dependence. US Department of Health and Human Services, Rockville, Maryland, USA June 2000 (ISBN 1-58763 007 9).

13 Zhu SH, Anderson CM, Johnson CE, et al. A centralised telephone service for tobacco cessation: the California experience. Tobacco Control 2000;9/suppl II):ii48-55.

14 Wakefield M, Borland R. Saved by the bell: the role of telephone helpline services in the context of mass-media anti-smoking campaigns. Tobacco Control 2000;9:117-19.

15 Census and Statistics Department. Special Topics Report No. 20. General Household Survey 1998. Hong Kong: Government Printer, 2000.

16 Prochaska JO, Goldstein MG. Process of smoking cessation: implication for clinicians. Clin Chest Med 1991;12:727-35.

17 Heatherton TF, Kozlowski LT, Frecker RC, et al. The Fagerstrom test for nicotine dependence: a revision of the Fagerstrom tolerance questionnaire. Br J Addict 1991;86:1119-27.
18 Census and Statistics Department. Report No. 5. Thematic Household Survey 2000. Hong Kong: Government Printer, 2000.

19 Prout MN, Martinez O, Ballas J, et al. Who uses the smoker's quitline in Massachusetts? Tobacco Control 2002;11(suppl II):ii74-5.

20 Fagerstrom KO, Schneider N. Measuring nicotine dependence: a review of the Fagerstrom tolerance questionnaire. J Behav Med 1989:12:159-82.

21 Silagy C, Lancaster T, Stead L, et al. Nicotine replacement therapy for smoking cessation. Cochrane Database Syst Rev 2002;20:CD000146.

22 Davis SW, Cummings KM, Rimer BK, et al. The impact of tailored self-help smoking cessation guides on young mothers. Health Educ $Q$ 1992; 19:495-504.

23 Orleans CT, Boyd NR, Bingler R, et al. A self-help intervention for African American smokers: tailoring cancer information service counselling for a special population. Prev Med 1998;27:S61-70.

24 Thompson B, Kinne S, Lewis FM, et al. Randomized telephone smokingintervention trial initially directed at blue-collar workers. J Natl Cancer Inst Monogr 1993; 14:105-12.

25 Balanda KP, Lowe JB, O'Connor-Fleming ML. Comparison of two self-help smoking cessation booklets. Tobacco Control 1999;8:57-61.

26 Hughes JR, Goldstein MG, Hurt RD, et al. Recent advances in the pharmacotherapy of smoking. JAMA 1999;281:72-6.

27 Riemsma RP, Pattenden J, Bridle C, et al. Systematic review of the effectiveness of stage based interventions to promote smoking cessation. $B M J$ 2003;326: $1175-7$

28 Velicer WF, Prochaska JO, Rossi JS, et al. Assessing outcome in smoking cessation studies. Psychol Bull 1992;111:23-41.

29 Gourlay SG, Benowitz NL, Forbes A, et al. Determinants of plasma concentrations of nicotine and cotinine during cigarette smoking and transdermal nicotine treatment. Eur J Clin Pharmacol 1997:51:407-14.

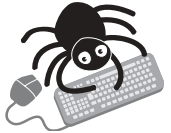

Please visit the Tobacco

Control website [www. tobaccocontrol. com] for a link to the full text of this article.
How much downside? Quantifying the relative harm from tobacco taxation N Wilson, G Thomson, M Tobias, T Blakely

Objective: To estimate the loss of life expectancy attributable to tobacco taxation (via financial hardship and flow-on health effect) in New Zealand.

Design: Data were used on the gradients in life expectancy and smoking by neighbourhood socioeconomic deprivation and survey data on tobacco expenditure. Three estimates were modelled of the percentage of the crude association of neighbourhood deprivation with life expectancy that might be mediated via financial hardship: 100\%, 50\%, and 25\% (best estimate). From this information the impact of tobacco taxation on life expectancy was estimated.

Main results: For the total population, the estimated loss of life expectancy due to tobacco tax ranged from 0.005 years to 0.027 years. For people living in the most deprived $30 \%$ of neighbourhoods, the range was 0.009 to 0.044 years (that is, 3 to 16 days of lost life expectancy). For the total population the loss of life expectancy attributable to tobacco tax ranged from 119 to 460 times less than that attributable to deprivation. The loss of life expectancy attributable to tobacco tax was 42 to 257 times less than that attributable to smoking.

Conclusions: The estimated harm to life expectancy from tobacco taxation (via financial hardship) is orders of magnitude smaller than the harm from smoking. Although the analyses involve a number of simplistic assumptions, this conclusion is likely to be robust. Policy makers should be reassured that tobacco taxation is likely to be achieving far more benefit than harm in the general population and in socioeconomically deprived populations. \ Journal of Epidemiology and Community Health 2004;58:451-454. 